Published online 2016 January 23.

Letter

\title{
Cerebral Neurocysticercosis due to Taenia martis, the Third Species That Needs Attention
}

\author{
Beuy Joob" ${ }^{1, *}$ and Viroj Wiwanitkit ${ }^{2}$ \\ ${ }^{1}$ Sanitation 1 Medical Academic Center, Bangkok, Thailand \\ ${ }^{2}$ Faculty of Biological Science, Joseph Ayobabalola University, Ikeji-Arakeji, Nigeria \\ ${ }^{*}$ Corresponding author: Beuy Joob, Sanitation 1 Medical Academic Center, Bangkok Thailand. Tel:+66-24658292, Fax:+66-24658292, E-mail: beuyjoob@hotmail.com \\ Received 2015 July 27; Accepted 2015 July 28.
}

Keywords: Cerebrum, Cysticercosis, Species

\section{Dear Editor,}

One of the most important cestode infestations is cysticercosis. It can affect the cerebrum hemisphere and result in neurocysticercosis. The main cause of cerebral neurocysticercosis is Taenia solium (1). However, there are continuous reports on new species able to induce cerebral neurocysticercosis. The second species in human beings mentioned to cause cerebral neurocysticercosis is Taenia asiatica (2). The disease is sporadically seen in tropical East and Southeast Asia. However, there is a recent report on the third species cerebral neurocysticercosis (3). Brunet et al. reported neurocysticercosis due to Taenia martis in an immunocompromised host. In fact, Taenia martis has been described in human beings for a few years but not in brain (3). The new species cerebral neurocysticercosis is an actual challenge. The exact pathophysiological process of infection, epidemiology and disease transmis- sion are still unknown for neurology and infectious diseases specialty fields, which needs further studies.

\section{References}

1. Bouteille B. [Epidemiology of cysticercosis and neurocysticercosis]. Med Sante Trop. 2014;24(4):367-74. doi:10.1684/mst.2014.0378. [PubMed: 25296005]

2. Galán-Puchades M, Fuentes MV. Neurocysticercosis, Taenia asiatica and Cheju Island in Korea. Trends Parasitol. 2001;17(10):469-70. doi:10.1016/s1471-4922(01)02089-x. [PubMed:11642258]

3. Brunet J, Benoilid A, Kremer S, Dalvit C, Lefebvre N, Hansmann Y, et al. First Case of Human Cerebral Taenia martis Cysticercosis. J Clin Microbiol. 2015;53(8):2756-9. doi: 10.1128/JCM.01033-15. [PubMed: 26019196]

4. Eberwein P, Haeupler A, Kuepper F, Wagner D, Kern WV, Muntau B, et al. Human infection with marten tapeworm. Emerg Infect Dis. 2013;19(7):1152-4. doi: 10.3201/eid1907.121114. [PubMed: 23763821] 